\title{
A ARTE CIRCENSE E SEU DIÁLOGO COM A EDUCAÇÃO FÍSICA: UMA EXPERIÊNCIA NO INSTITUTO FEDERAL DE EDUCAÇÃO, CIÊNCIA E TECNOLOGIA DO RIO GRANDE DO SUL
}

\author{
M. A. OST $^{1}$, M. VIANNA ${ }^{2}$, G. S. PEREIRA ${ }^{3}$ \\ Instituto Federal de Educação, Ciência e Tecnologia do Rio Grande do Sul \\ ORCID ID: https://orcid.org/0000-0003-1205-210X \\ mariana.ost@osorio.ifrs.edu.br
}

Submetido 10/04/2020 - Aceito 17/09/2020

DOI: $10.15628 /$ holos.2020.9883

\begin{abstract}
RESUMO
Este artigo apresenta uma experiência de integração entre arte circense, Educação Física e outros componentes curriculares que culminou na produção de um espetáculo intitulado "Le Cirque: Cabeças Coloridas". A proposta foi criada e executada por estudantes do Ensino Médio Integrado do Campus Osório - Instituto Federal de Educação, Ciência e Tecnologia do Rio Grande do Sul - no ano de 2018, tendo como espectadores a comunidade escolar. As atividades que resultaram no espetáculo tiveram como principal objetivo oportunizar aos estudantes desenvolverem suas habilidades artísticas, físicas, audiovisuais, culturais, intrapessoais e interpessoais, de modo a explorá-las de acordo com suas aproximações e predisposições. Para isso, o espetáculo foi pensado de maneira a inspirar os espectadores a
\end{abstract}

partir da arte circense na perspectiva da cultura corporal de movimento, considerando a importância de promover o acolhimento de todas as pessoas e de contribuir para que explorassem os diferentes estímulos dessa experiência única. Como principal contribuição da proposta, destacam-se as habilidades artísticas, criativas e sociais desenvolvidas, os talentos individuais explorados pelos estudantes, bem como sua autoconfiança. Ainda, por conta da dinâmica da proposta, cabe ressaltar que a integração entre os participantes foi oportunizada não somente no que se refere às trocas efetivadas entre eles, mas também pelo contato constante com o público, fundamental para que a "magia" do espetáculo circense pudesse acontecer.

PALAVRAS-CHAVE: Educação Física, arte circense, prática curricular integrada.

\section{CIRCUS ART AND PHYSICAL EDUCATION: DIALOGUE AND EXPERIENCE AT FEDERAL INSTITUTE OF EDUCACION, SCIENCE AND TECHNOLOGY OF RIO GRANDE DO SUL}

\begin{abstract}
This paper presents an experience of integration among Circus Art, Physical Education and other curricular components that culminated in the production of a show entitled "Le Cirque: Cabeças Coloridas". The proposal was created and implemented by studentes of Integrated High School at Federal Institute of Education, Science and Technology of Rio Grande do Sul (Instituto Federal de Educação, Ciência e Tecnologia do Rio Grande do Sul) in 2018, with school Community as spectators. Activities' main objective involved giving students opportunity to develop their artistic, physical, audiovisual, cultural, intrapersonal and interpersonal skills, in order to explore them according to their approaches and predispositions.
\end{abstract}

For this, the show was designed to inspire people to know Circus Art from the perspectives of body movement culture, considering the importance of promoting shelter for people and helping them to explore the different stimuli of this unique experience. Contributions of this proposal for all participants is the artistic, creative and social skills developed, as well as their self-confidence and individual talents. Still, due to the activity dynamics, it is worth mentioning that the integration among the participants was made possible not only their exchanging experiences, but also the constant contact with the public, which was essential for the "magic" of circus show.

KEYWORDS: Physical Education, Circus Art, integrated curricular praxis. 


\section{INTRODUÇÃO}

A arte circense, desde sua origem, exerce fascínio e encantamento em seus espectadores. Assim, enquanto uma importante forma de manifestação da cultura, constitui-se como uma expressão desse meio em constante modificação. Há de destacar, que por seu caráter dinâmico, diversificado e flexível, faz o circo contemporâneo, a partir da articulação entre diferentes artes e da promoção de atividades que se transformam e vão se adequando às mudanças da sociedade. Isso possibilita manter um público cativo, já que é considerada uma das mais atrativas atividades de entretenimento, como observaram Coelho e Minatel (2001). Em síntese, conforme esses autores, o circo é um objeto social que tem um valor historicamente construído e que, a todo tempo, busca uma identidade diante das mais diversas pressões sociais.

Destaca-se que não há consenso na literatura sobre a origem das artes circenses ou algum registro referenciado que date a primeira apresentação formal de circo. Alguns estudos revelam que desde os primórdios das sociedades antigas, a arte do entretenimento vem sendo desenvolvida, retratada, bem como permeando a vida dos mais diferentes povos, consagrando-se como uma arte repleta de mitos, crenças e fantasias, especialmente inspirados no desconhecimento (Duprat \& Bortoleto, 2007). É com essa finalidade que o circo antigo e moderno se constrói, como uma forma de encantamento, de fuga, de abstração do mundo real. Foi entre os séculos XVIII e XIX que o circo apareceu e estruturou-se como uma arte com identidade própria, apesar de grande parte de seus saberes terem sido elaborados ao longo de milhares de anos. Nesse período, denominado circo tradicional ou moderno, destacam-se as demonstrações equestres em espaços fixos, tais como anfiteatros e teatros e, até mesmo, espetáculos com estrutura e rigor militar, que se mostravam bem diferentes das características que podem ser observadas entre os saltimbancos, equilibristas, saltadores e cômicos da Idade Média ou mesmo do Renascimento.

Por sua vez, a arte circense no Brasil tem suas origens no século XVIII, tendo como protagonistas artistas de rua, considerados perigosos e indesejáveis na Europa, que encontraram meios para sobreviver e manifestar sua arte considerada popular, incorporando-se a poetas e cantores nas freguesias do Brasil Colônia. Com o passar do tempo, esses artistas foram influenciados pela nova arte circense europeia, através de pantomimas, demonstrações equestres e mágicas, constituindo o que seria conhecido como circo moderno. Ao longo do século XX, essa manifestação artística seria controlada por famílias de artistas através de companhias circenses, que embora comerciais, mantinham ainda uma organização social próxima às populações humildes do interior do país. Ainda que houvesse novas transformações a partir dos anos 1970, tendo em vista o desenvolvimento enquanto empreendimentos comerciais, destaca-se que tradições de uma arte popular, mesmo com esse novo contexto, ainda foram preservadas (Kronbauer \& Nascimento, 2013).

Nota-se que houve uma gradual transição entre a maneira oral de transmissão dos saberes circenses, reservada a alguns poucos privilegiados, à sistematização e sua aplicação em escolas especializadas. Essa transformação permitiu uma abertura desse campo artístico a profissionais e estudiosos de diferentes áreas de atuação voltadas à manifestação da cultura corporal de 
movimento. A referida dinâmica sociocultural não foi diferente com os profissionais da Educação Física, já que o novo modelo de circo possibilitou considerar esse importante saber da cultura corporal como parte dos conteúdos que devem ser abordados no contexto educacional, mais especificamente nas aulas desse componente curricular (Duprat \& Bortoleto, 2007).

Ainda, estudos como os de Ontañón, Duprat e Bortoleto (2012) destacam que o "repentino" interesse nas atividades circenses envolveu um modismo que surgiu entre o final do século XX e o início do XXI, com a maior divulgação dos espetáculos circenses pela mídia de massa. A disseminação entre o público levou a um crescimento da procura, por parte dos professores de Educação Física, que tinham em vista novos e atrativos conteúdos para suas aulas, fator que permitiu transpor saberes seculares a um público mais amplo (Ontañón, Duprat \& Bortoleto, 2012), desejoso de encontrar novas formas de expressão cultural, como a corporal. Isso porque a Educação Física deixou de operar com relações "binárias", que dividiam os discentes entre "aptos" ou "inaptos", passando a reconhecer, a partir de seus profissionais, uma "multiplicidade de possibilidades de práticas corporais, pautadas na vivência, no desafio, na criatividade e na proposição" (Figueira \& Jaeger, 2005, p. 137). Essas possibilidades envolvem o compartilhamento de experiências e a construção de novos saberes corporais a partir de atividades circenses que envolvam equilíbrio, acrobacias e saltos, por exemplo.

\section{A ARTE CIRCENSE E A EDUCAÇÃO FÍSICA COMO POSSIBILIDADE INTERDISCIPLINAR EM POTENCIAL}

Entendemos o espaço escolar como um dos principais meios de transmissão e produção de cultura, constituindo-se enquanto abrigo para diferentes manifestações artísticas promovidas pela sociedade. Desse modo, é possível considerar a arte circense como uma parte importante da cultura corporal de movimento, o que, por si só, já justifica sua inclusão no universo educativo, por se tratar de um conteúdo significativo e necessário (Duprat \& Bortoleto, 2007). Por sua vez, ao considerarmos Arte e Educação Física enquanto componentes curriculares da área das linguagens, faz-se clara a possibilidade de fluidez do caminho para a interdisciplinaridade, visto que ambas conversam entre si de maneira natural. Isso é mais evidente quando se conta com concepções dos docentes sob a mesma perspectiva, com visões de educação e de mundo na ótica da valorização das diferentes manifestações da cultura, seja ela corporal de movimento ou artísticas.

Além disso, historicamente, há certa cumplicidade entre esses componentes, visto que, ainda existe um rótulo de disciplinas secundárias ou recreativas no contexto escolar, consideradas como menos importantes pela sociedade de modo geral. Conforme afirmam Falkenbach e Stampe (2000, p. 1), “a Educação Física e Artes por muito tempo, e ainda atualmente, recebem o estereótipo de disciplinas menos importantes, que devem fazer parte da escola por mero cumprimento das leis". Assim, percebe-se que essa maneira de ver esses dois componentes, sem dúvidas, ignora que cada disciplina de ensino tem importância concreta no desenvolvimento global do indivíduo.

Logo, a construção de propostas interdisciplinares entre as duas disciplinas, além de contribuir para valorização de ambas, eleva as possibilidades de produção de conhecimentos e 
significados, assumindo extrema relevância para o meio escolar na medida em que contribui para o desenvolvimento integral dos estudantes e, consequentemente, para a transformação social.

Com relação à nossa realidade e, diante do contexto e das políticas que constituem a proposta dos Institutos Federais, vê-se como pertinente destacar que os documentos orientam para esse caminho, onde a educação integral constitui-se como um dos princípios basilares dessa estrutura. De acordo com o Plano Pedagógico de Curso do Ensino Técnico em Informática Integrado ao Ensino Médio do Campus Osório - IFRS:

Será estimulado o trabalho com projetos que sejam articulados entre diferentes áreas do conhecimento. Nessa articulação, pretende-se um trabalho docente interdisciplinar, garantindo, assim, aos discentes do Curso a oportunidade de perceber a construção do conhecimento a partir do compartilhamento de saberes e de experiências, e de desenvolver olhares, concepções e práticas globais sobre/na realidade em que vivem e atuam (IFRS, 2015, p. 26).

Diante do exposto, vê-se como é importante destacar "[...] que o desenvolvimento de práticas pedagógicas integradoras não depende, apenas, de soluções didáticas, elas requerem, principalmente, soluções ético-políticas" (Araújo \& Frigotto, 2015, p. 64). Dessa forma, demonstrar o papel social da escola, a partir de práticas como a explicitada, considerando suas relações com a realidade, coloca-se como aspecto fundante para a formação humana e para o desenvolvimento crítico dos estudantes.

Por sua vez, a lei n.o 13.278/2016, que inclui as artes visuais, a dança, a música e o teatro nos currículos dos diversos níveis da educação básica e altera a Lei de Diretrizes e Bases da Educação Nacional (LDB - Lei 9.394/1996), corrobora com a legitimidade dessas formas de manifestação da cultura e da sua importância na formação básica. Ainda, estabelece o prazo de cinco anos para implantar esses componentes curriculares na educação infantil, ensino fundamental e médio.

Assim, as possibilidades de diálogos são inúmeras, visto que o lúdico, a dança, o teatro e a expressão corporal são manifestações que fazem parte dos dois universos. Apresenta-se, ainda, a consideração relativa à pluralidade no âmbito da arte e da cultura, o que torna o "terreno" ainda mais enriquecedor para o desenvolvimento de práticas pedagógicas. Elas se relacionam através de uma educação multicultural, reconhecendo que os membros de uma comunidade escolar possuem diferentes códigos culturais, que influenciam em suas práticas sociais e em seus processos de ensino-aprendizagem (Richter, 2012). Se valorizadas em sua heterogeneidade, reconhecendo seus pontos de convergência e divergência, ela terá plena capacidade para promover um ensino realmente significativo para os envolvidos.

\section{A CONSTRUÇÃO DE UM ESPETÁCULO CIRCENSE NO CAMPUS OSÓRIO DO IFRS: OS ESTUDANTES/ARTISTAS ESTRELANDO UMA ATIVIDADE INTEGRADA}

\subsection{Metodologia de análise}

Este artigo constitui-se enquanto um relato de experiência originado pela atuação com turmas do segundo ano do EMI, no componente curricular Educação Física, o qual enfatizou a arte 
circense como orientadora das práticas pedagógicas propostas ao longo de um trimestre letivo. Seu estudo procurou combinar abordagens qualitativa e quantitativa, pois, para além dos relatos e das observações das práticas durante o percurso da atividade, também se definiu pela coleta de dados numéricos. Isto permitiu subsidiar a avaliação do desenvolvimento da atividade, tanto pela relação que os estudantes puderam considerar sobre suas atuações no projeto, quanto pela observância que tiveram no que se refere às práticas dos demais colegas.

Deste modo, tratando-se de ferramentas utilizadas para a análise e a discussão dos dados, enfatiza-se a opção pelo uso de um questionário semiestruturado, contendo cinco questões, distribuídas em fechadas e abertas, de modo a "levantar informações escritas por parte dos sujeitos pesquisados com vistas a conhecer a opinião dos mesmos" (Severino, 2007, p. 125). Assim, ao final da experiência, foi proposto o questionário para proporcionar que os estudantes participantes pudessem avaliar a proposta. Isso permitiu que identificassem falhas e realizassem uma autoavaliação de suas atuações, considerando seus protagonismos desde o planejamento das atividades até a finalização do projeto. Reitera-se, portanto, no percurso de análise sobre os dados, o olhar para as falas dos estudantes com ênfase às definições que contornam um estudo qualitativo, sem perder de vista, também, os levantamentos numéricos proporcionados pelo questionário, que orientaram a análise em aspectos quantitativos.

\subsection{O espetáculo}

O espetáculo "Le Cirque: Cabeças Coloridas" foi uma produção inspirada nas artes circenses, criada e executada pelos estudantes dos 2.o anos do Ensino Médio Integrado do Campus Osório - Instituto Federal de Educação, Ciência e Tecnologia do Rio Grande do Sul, entre setembro e dezembro de 2018. Desenvolvida a partir de uma proposta do componente curricular de Educação Física, a atividade contou ainda com a participação da comunidade escolar, que contribuiu para que a prática se efetivasse a partir de pressupostos de interdisciplinaridade e formação integral, princípios que orientam a proposta dos Institutos Federais. A ação teve como principal objetivo, além de proporcionar lazer e diversão aos espectadores, oportunizar aos estudantes que fossem capazes de entrar em contato com suas habilidades artísticas, físicas, audiovisuais, culturais, intrapessoais e interpessoais, de modo a explorá-las de acordo com suas aproximações e predisposições. Para isso, o evento foi pensado de maneira a inspirar os espectadores, de modo que o grupo foi constituído considerando a importância de promover o acolhimento de todas as pessoas e de contribuir para que explorassem os diferentes estímulos dessa experiência única. Como principal contribuição da proposta aos participantes, pode-se destacar as habilidades artísticas, criativas e sociais desenvolvidas, os talentos individuais explorados pelos estudantes, bem como sua autoconfiança. Ainda, por conta da dinâmica da proposta, cabe ressaltar que a integração entre os participantes foi oportunizada não somente no que se refere às trocas efetivadas entre eles, mas também pelo contato constante com o público, fundamental para que a "magia" do espetáculo circense pudesse acontecer.

Como metodologia da proposta, a mesma iniciou na aula de apresentação do conteúdo, em que se propôs um circuito de atividades e desafios corporais como: saltos e rolamentos, equilíbrios estáticos e dinâmicos, manipulação de bolas e atividades rítmicas. Essa proposta foi pensada como estratégia de encorajamento dos estudantes, com vista a servir de estímulo para 
que aceitassem e se sentissem capazes de assumir o desafio de criar um espetáculo baseado na arte circense. Ao final dessa aula de iniciação, discutiu-se a respeito da proposta, que, de imediato, foi bem recebida pela grande maioria dos estudantes das quatro turmas, que somavam um total de 92 participantes envolvidos no projeto.

Ressalta-se que a proposta inicial, bem como a ideia de trazer os estudantes para o mundo das artes circenses, a partir da contextualização e da prática de atividades que se assemelhavam ao que iriam desenvolver mostrou-se como efetiva e, pode-se dizer que fez toda a diferença no que se refere ao encorajamento dos estudantes, facilitando que os mesmos acreditassem na ideia e, a partir disso, produzissem suas próprias criações para o espetáculo.

A construção se deu ao longo do mês de setembro, em encontros semanais nas aulas de Educação Física. E, além do desenvolvimento do conteúdo de atividades circenses, ao longo do trimestre, também foram trabalhados outros, mas com ênfase maior na produção do espetáculo. No desenrolar das aulas, foram surgindo ideias individuais e coletivas e todas elas eram apresentadas ao grande grupo, com a preocupação de serem socializadas pela professora nas demais turmas. Em determinado momento, após aproximadamente 15 dias do lançamento da proposta, percebemos a necessidade de dividir todos os estudantes em comissões de trabalho e escolher um diretor por turma, para assim, facilitar o desenvolvimento do projeto. $E$, com essa divisão em comissões, também surgiu a necessidade de realizar encontros e ensaios no turno inverso às aulas.

As comissões de trabalho foram criadas pensando em focar nas especificidades do espetáculo e otimizar a organização e o tempo. A distribuição dos estudantes nas comissões foi feita a partir das suas escolhas, tendo como base as habilidades e interesses de cada um.

Assim, as comissões de trabalho se configuraram da seguinte maneira:

1. direção geral: quatro diretores, sendo um estudante de cada turma escolhido para compor essa comissão;

2. roteiro: cinco estudantes realizaram a coleta de ideias e informações que as turmas trouxeram no início dos trabalhos e construíram o roteiro a partir desse apanhado inicial;

3. comunicação: 10 componentes que atuaram na divulgação do evento, bem como nas criações de logotipo, mídias, cartazes e ingressos; responsáveis também pelas coberturas fotográficas;

4. cenografia: 18 estudantes foram responsáveis pela produção/apoio na composição do figurino, maquiagem, cenário, troca de palco, confecção de coxias e demais apoios de bastidores;

5. dança: 11 dançarinos realizaram a dança de abertura do espetáculo;

6. malabares: seis estudantes fizeram apresentação de números de manipulação de objetos como diabolô, lenços e bolas. E ainda o equilíbrio no cilindro;

7. acrobacia: 11 componentes fizeram parte desta comissão, realizando saltos, manobras e equilíbrios ritmados chegando próximos aos limites corporais;

8. mágica: seis participantes realizaram pesquisas e estudos relativos a habilidades de ilusionismo e apresentaram alguns números de mágica; 
9. atuação/humor: 14 integrantes se dividiram e apresentaram dois números de humor;

10. audiovisual: seis estudantes pesquisaram sobre efeitos sonoros, músicas de acordo com cada número e ficaram responsáveis por operar a mesa de som e luz;

11. vendas: 20 estudantes fizeram parte do grupo da "Praça de alimentação", em que deveriam organizar a produção, as bancas e a decoração desse espaço. Assim, foram vendidos doces de festa, bolos e pipocas, todos produzidos pelos próprios estudantes a partir de suas doações.

12. banda: 10 integrantes que finalizaram o espetáculo com a apresentação de duas músicas;

A definição do tema do espetáculo teve como inspiração os Circos Franceses, fazendo relação com o conteúdo que estava sendo trabalhado no componente curricular História. Sobre as parcerias desta atividade, cabe destacar que foi feito um convite, logo no início do planejamento, a todos os docentes que atuavam no segundo ano para serem parceiros da proposta. A ideia inicial foi construir coletivamente uma atividade integrada na qual os docentes pudessem participar da proposta, caso desejassem.

Os componentes curriculares que integraram a proposta, além da Educação Física, foram Química, História e Gestão de Pessoas, caracterizando-a como uma atividade integrada. Cabe destacar que, nas matrizes curriculares dos cursos EMI ofertados no Campus Osório, o componente curricular Artes não está contemplado no 2 음 ano, logo, no que se refere à proposta avaliativa, não foi possível a relação direta com esse componente. Nas disciplinas de História e Gestão de Pessoas, foi possível realizar uma maior fluência no projeto, pois os estudantes tiveram que estudar sobre a história da arte circense no período da Revolução Francesa. Em Gestão de Pessoas, foram colocados em prática conhecimentos relativos às relações interpessoais, bem como outros mais operacionais da área da Administração, a partir do necessário planejamento de eventos e vendas na "Pracinha de Alimentação". Salienta-se, nesse sentido, que a participação de ambos os componentes na proposta foi considerada como avaliativa. Em Química e Programação de Computadores, o envolvimento com o espetáculo ocorreu de forma mais isolada, em dois momentos diferentes do espetáculo, na qual, por exemplo, a utilização de assuntos da Química foi necessária aos atos de mágica.

Sobre essa questão da interdisciplinaridade, que pode ser observada na proposta, ressaltase que é fato que ainda existe dificuldade em construir ideias e viabilizar práticas integradas no Ensino Médio. Temos como hipótese que essa dificuldade esteja ligada ao fato de que os docentes têm diferentes concepções de educação e reconhecimento da interdisciplinaridade, havendo, ainda, certo distanciamento entre as áreas e, dessa forma, poucos momentos de construção de planos e estratégias de ensino de forma coletiva.

Nessa mesma linha, Goulart et al. (2012) revelam que a interdisciplinaridade acontece naturalmente se houver sensibilidade para o contexto, mas sua prática e sistematização demandam trabalho didático de um ou mais professores. Motivos como a falta de tempo, interesse ou preparo, o exercício docente, na maioria das vezes, ignora a intervenção de outras disciplinas na realidade ou no fato que está sendo trabalhado com os alunos. 


\subsection{A recepção do público...}

No dia do espetáculo foi preparada uma recepção às crianças, que eram as convidadas principais, na entrada do campus, onde um grupo de artistas em pernas de pau, mágicos e palhaços os receberam e conduziram os grupos ao auditório, com o cuidado de que o encantamento fosse ocasionado desde o primeiro olhar. Além do espetáculo, as turmas produziram uma "Pracinha de Alimentação", com venda de bolos, brigadeiros, pipoca e refrigerante, que atendia ao público antes e depois do espetáculo. O dinheiro arrecadado foi dividido entre as quatro turmas como crédito para utilizarem em suas formaturas.

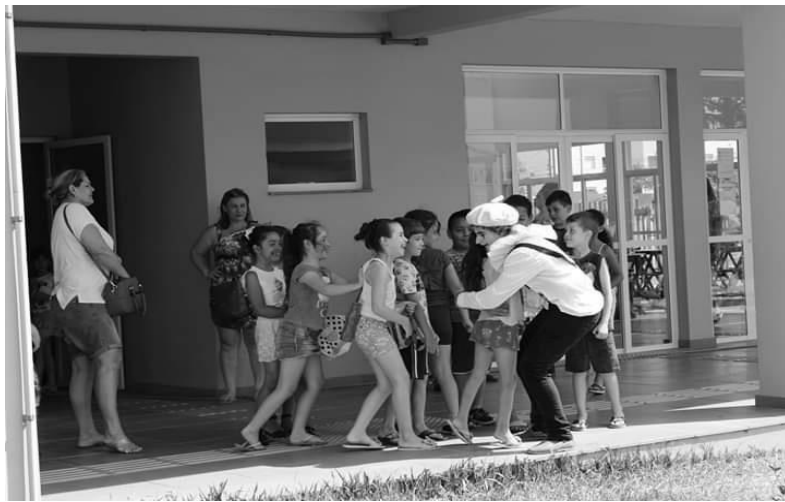

Figura 1: Crianças sendo recebidas por um estudante Fonte: dos autores.

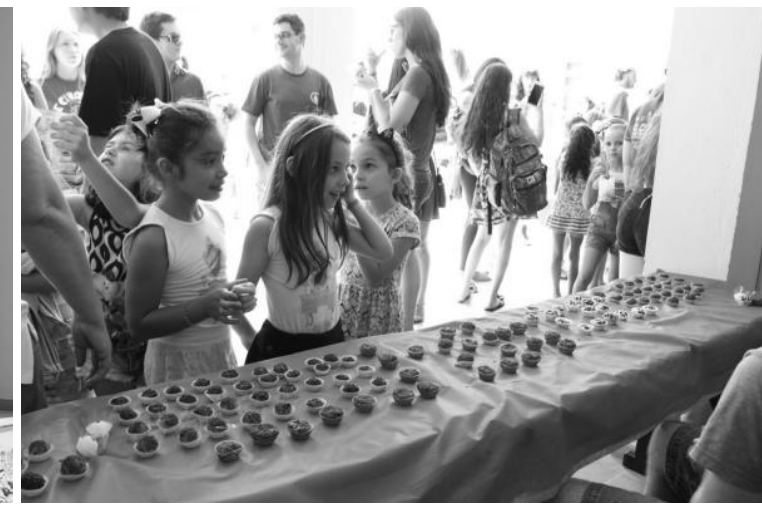

Figura 2: Crianças na "Pracinha de alimentação" Fonte: dos autores.

Compuseram o público do espetáculo: os estudantes das demais turmas e servidores, alguns familiares e 62 estudantes, com idade entre seis e oito anos, de escolas da rede municipal, que assistiram ao espetáculo e abrilhantaram o conjunto da obra. Do início ao fim, interagiram com os artistas fazendo perguntas às personagens e vibrando a cada número. Nota-se que, além de ser uma atividade caracterizada nos moldes de uma prática de ensino que se desenvolveu entre os sujeitos internos ao campus, como estudantes e professores, o espetáculo em si cumpriu com o papel diretamente relacionado aos compromissos de uma proposta de extensão, de interagir e proporcionar arte e cultura para a comunidade, externando os saberes produzidos internamente na instituição.

\subsection{A visão do estudante}

Foram obtidas 90 respostas do questionário aplicado aos 92 participantes envolvidos na proposta. Destes, 87 estudantes atribuíram notas acima de oito, sendo 48 optaram por marcar a nota máxima com relação à avaliação da atividade integrada.

Os estudantes relataram, em sua maioria, análises positivas, de encantamento e de valorização do projeto. Alguns estudantes relataram que se sentiram sobrecarregados e que sofreram por conta da necessidade de que houvesse muitos ensaios extras, alegando essa questão como um ponto negativo da proposta. Ainda, seis relatos demonstraram descontentamento com a falta de coleguismo e empenho nas atividades por parte de alguns participantes.

Diversos estudantes revelaram que gostariam de ter a oportunidade de fazer uma nova apresentação e que o espetáculo em si surpreendeu muitas pessoas, superando inclusive as expectativas dos próprios participantes. Outra questão que merece destaque é relacionada ao 
desenvolvimento e fortalecimento das relações interpessoais, tendo em vista que os estudantes disseram que a proposta contribuiu muito para a união de cada uma das turmas, impactando positivamente no fator integração; Além disso, destacaram a oportunidade de resolver, de forma autônoma, conflitos que surgiram ao longo da proposta, aprendendo com o desenrolar dos mesmos.

Quando questionados sobre quais contribuições a experiências a construção do espetáculo "Le Cirque: cabeças coloridas" trouxe para o desenvolvimento pessoal, as respostas foram bem diversas, porém grande parte revelou que habilidades muitas vezes não tão exploradas em atividades tradicionais/formais no meio escolar, como expressão corporal, artística e de relações sociais, foram colocadas em pleno desenvolvimento, como mostra o seguinte depoimento:

Ajudou a desenvolver nosso protagonismo enquanto estudantes e organizadores do evento. Assim como nos ajudou a perceber nossas habilidades, em que éramos bons, incentivando a arte dentro do nosso Campus. (Depoimento de um discente envolvido no projeto)

Relataram também que se sentiram desafiados, estimulados a desenvolver a criatividade, a mudar estratégia para resolução de problemas/conflitos, a ampliar o olhar para o todo de um projeto, para o trabalho coletivo. Ainda, foi interessante perceber a partir dos relatos que, como os estudantes participaram da proposta em comissões que escolheram, os mesmos sentiram seus conhecimentos anteriores valorizados, se sentiram úteis, capazes, revelando confiança para utilizar suas habilidades nas áreas de interesse como fotografia, música, costura, maquiagem, dramaturgia, literatura, carpintaria, desenho, entre outras, potencializando assim os seus conhecimentos e possibilitando o aprender com o outro, o que resultou uma rede de compartilhamento de saberes.

A fim de ilustrar sobre as experiências vividas pelos estudantes trazemos alguns relatos buscando exemplificar o quão significativo foi a participação na proposta:

Foi uma oportunidade linda que me possibilitou a participação e contemplação de diversas artes e expressões e que foram de tremenda importância para integração das turmas;

O circo propôs uma atividade ainda não praticada no Instituto, fazendo com que a atividade atraísse mais do que as outras. Desenvolveu habilidades múltiplas, muito conhecimento e esforço de todos que colaboraram. O espetáculo foi incrível, mesmo com alguns erros;

Eu literalmente me entreguei de corpo e alma! Chorei durante o espetáculo. Ver como foi dureza a execução e ficou tão bom, compensou as muitas horas de trabalho;

Adorei!! foi muito importante para sairmos um pouco daquele esquema quadro e prova, além de que cada um pôde escolher o que faria no circo, o que deixou a oportunidade para mostrar o que fazemos de melhor. Minha sugestão é que esse tipo de atividade seja frequente, pois é fundamental para construção da mentalidade de trabalho em equipe (já que mesmo não sendo de todas as comissões, a maioria dos alunos ajudaram em todo o processo) e também para a estimular a criatividade dos alunos. (Depoimento dos discentes envolvidos no projeto).

Analisando os depoimentos dos estudantes, torna-se perceptível o quanto que a proposta, por seu caráter inédito e de valorização do protagonismo dos envolvidos, marcou a trajetória escolar e de vida dos participantes. Em especial, ressalta-se que a ação destacou-se pela emoção provocada, evidenciada nessas falas carregadas de sentimentos e sensibilidade, bem como na postura com a qual, em sua maioria, os estudantes desenvolveram seus papéis. Reafirma-se, 
diante disso, o quanto a proposta foi capaz de proporcionar vivências relacionadas à arte e à cultura, despertando, no meio escolar, emoções comuns de serem promovidas por essas áreas em diferentes espaços de valorização e desenvolvimento cultural. Para além disso, em relação aos depoimentos, destaca-se a ênfase atribuída à importância do trabalho coletivo e da integração das turmas que participaram da proposta, fatores imprescindíveis para que se perceba o sucesso de uma atividade integrada.

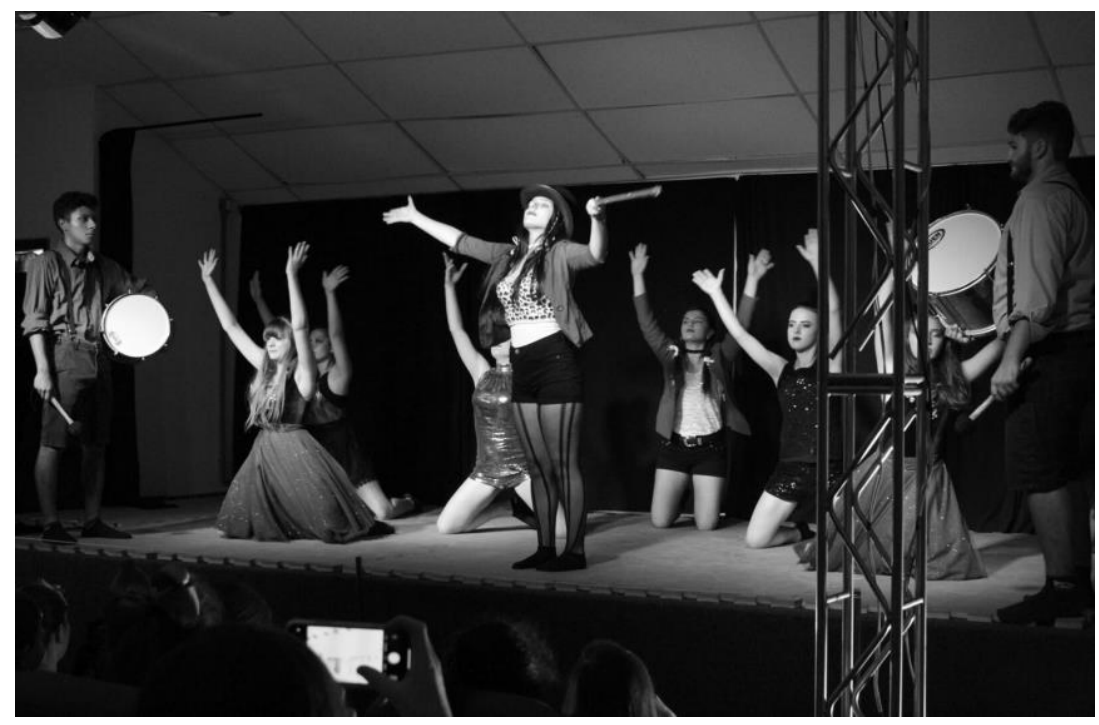

Figura 3: Apresentação do Le Cirque, destacando-se o trabalho coletivo dos estudantes.

Fonte: dos autores

Uma das mais marcantes experiências foi a que envolveu o estudante que interpretou Lelé, o palhaço. A função de Lelé não foi apenas ser um animador e divertir o público, mas servir de elo para as demais apresentações do espetáculo. Como um mediador e improvisador, Lelé possibilitou, sempre no intervalo das apresentações, que os participantes pudessem fazer a transição de uma atividade para outra, dando-lhes tempo para se preparar, se concentrar e mesmo corrigir alguma falha de última hora.

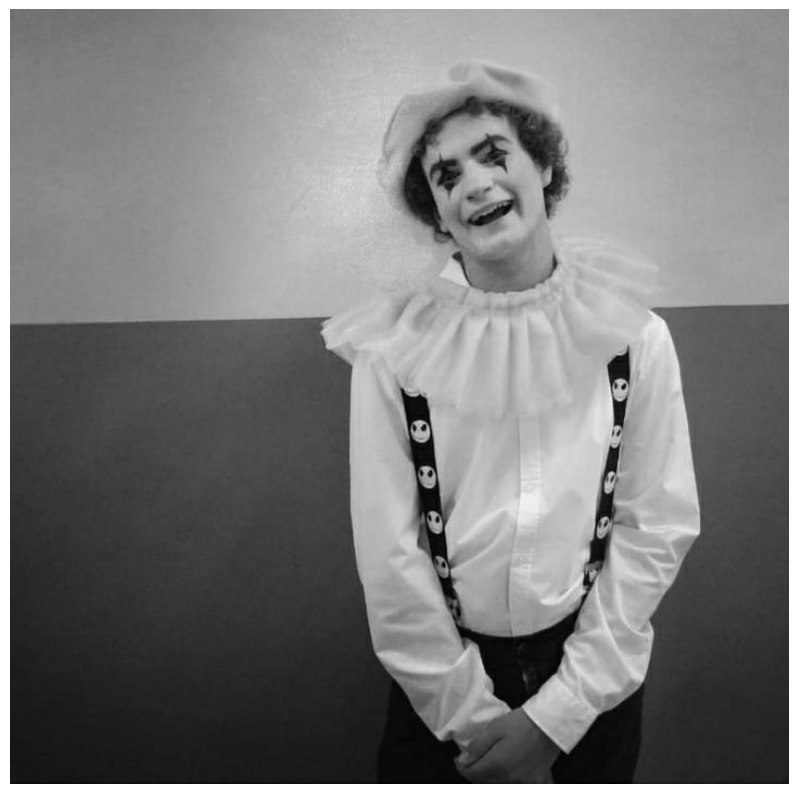

Figura 4: Estudante que protagonizou o espetáculo caracterizado como Lelé. Fonte: dos autores 
Para o estudante, foi uma das maiores experiências que a instituição lhe proporcionou:

Tenho orgulho em dizer que interpretei um "cabeça colorida", um multi tarefas do Le Cirque. Tenho orgulho em dizer que interpretei o Lelé. Ele foi malabarista, dançarino, mágico, um artista. Também foi mágico tudo que o Lelé proporcionou em minha vida.

Todos os ensaios para tornar esse espetáculo possível, todas as reuniões para decisões importantes, todos os encontros diários fizeram eu me sentir em casa e me sentir feliz e apaixonado.

Essa incrível experiência me aproximou do mundo artístico e me aproximou das crianças que assistiram ao nosso espetáculo. Abraçar as crianças, brincar com elas, perceber elas rindo das minhas palhaçadas, interagir com o público infantil, sentir...

Esse sentimento foi incrível, foi maravilhoso...

O Lelé se despediu dos palcos, se despediu do espetáculo, mas do meu coração nunca se despedirá.

O Lelé vive em mim! (Depoimento do estudante que interpretou Lelé, o palhaço).

Embora Lelé tenha desempenhado uma função primordial para o espetáculo, sendo sua principal figura pública, destaca-se os evidentes benefícios para reforço da autoestima e da integração do estudante com o grupo. O mesmo traz em seu depoimento aspectos fundamentais para uma proposta educativa de grande contribuição para formação integral dos sujeitos envolvidos como o desenvolvimento da inteligência emocional, da afetividade, da superação de desafios e do autoconhecimento. Ele destaca ainda a magia e o encantamento com relação às artes circenses, a valorização da construção do espetáculo, a aproximação e a troca com as crianças e a certeza que toda a experiência vivida ficará guardada na memória do estudante.

\section{CONSIDERAÇÕES FINAIS}

Acredita-se que o espetáculo "Le Cirque: cabeças coloridas" teve um impacto na vida escolar e pessoal dos estudantes. Desta forma, estimular trabalhos com a arte circense e Educação Física na escola revelam capacidade de influenciar os processos de ensino-aprendizagem, tornando-os mais significativos aos envolvidos. O diálogo entre arte circense e Educação Física possibilita desenvolver a criatividade, a capacidade de solucionar problemas, as habilidades corporais, a melhora de autoestima, e faz com que o estudante se sinta desafiado e vá para além de seus limites, aumentando seu repertório cultural, de movimento e artístico.

Após todas essas considerações, fica evidente que o crescimento individual e enquanto grupo foi um destaque da proposta. Para futuras práticas semelhantes a esta, ainda se faz necessário refletir sobre reformulações, de modo que, a partir da primeira experiência, possam ser promovidas adequações metodológicas na construção do espetáculo, bem como em fatores como período de realização e rotina de ensaios, tendo em vista que essa última é marcadamente intensa para os estudantes, principalmente considerando que, no mesmo período, eles precisam conciliar as demais atividades escolares.

Sobre a tentativa da interdisciplinaridade, cabe destacar que foi constituída, considerandoa como princípio indispensável para a constituição do ensino integrado, tendo em vista que, de acordo com Araújo e Frigotto (2015, p. 69), "alguns princípios podem ser orientadores para a organização de um currículo integrado: a contextualização, a interdisciplinaridade e o compromisso com a transformação social" (grifo nosso). Apesar de estar prevista e explícita nos documentos orientadores da proposta da Instituição, como nos Planos Pedagógicos de Curso e na 
Organização Didática do IFRS, ainda há dificuldades de concretizar essa prática entre os componentes curriculares.

Cabe evidenciar que, mesmo com aspectos a refletir e a melhorar, a experiência desta atividade interdisciplinar, que deu vida às artes circenses no currículo de ensino médio integrado, possibilitou enxergar uma aproximação entre estudantes e demais atores da comunidade escolar, tendo em vista o objetivo em comum de criar um grande espetáculo, um evento que pudesse ser constituído a partir das potencialidades de cada um, bem como de uma imensa pluralidade de ideias e de valorização da arte e cultura, tão necessárias e urgentes no ambiente educacional.

\section{REFERÊNCIAS}

Araujo, R. de L.; Frigotto, G. (2015). Práticas pedagógicas e ensino integrado. Educação em Questão, $52(38)$, 61-80. Recuperado de https://periodicos.ufrn.br/educacaoemquestao/article/download/7956/5723/.

Lei no 13.278, de 2 de maio de 2016. Altera o § 6 o do artigo 26 da Lei no 9.394/96, referente ao ensino da arte. Diário Oficial da União, Brasília, 2016. Recuperado de http://www.planalto.gov.br/CCIVIL 03/ Ato2015-2018/2016/Lei/L13278.htm.

Instituto Federal de Educação, Ciência e Tecnologia do Rio Grande do Sul. Projeto Pedagógico Curso Técnico em Informática Integrado ao Ensino Médio. Osório, 2015. Recuperado de https://osorio.ifrs.edu.br/site/midias/arquivos/201710684831636ppc administracao emi.pdf.

Coelho, M.; Minatel, R. (2011). Circo: A arte do riso e prática da reconstrução social. Topos, 5(1), 203-230.

Duprat, T.; Bortoleto, R. (2007). Educação Física escolar, pedagogia e didática das atividades circenses. Rev. Bras. Cienc. Esporte, Campinas, 28(2), 171-189. Recuperado de: http://www.revista.cbce.org.br/index.php/RBCE/article/viewFile/63/71

Falkenbach, A., \& Stampe, B. (2000). Educação física e artes: uma experiência interdisciplinar através do lúdico. Movimento (ESEFID/UFRGS), 6(13), 32-40. doi:https://doi.org/10.22456/1982-8918.11781

Figueira, M. L. M. \& Jaeger, A. A. (2005). Educação Física - Os lugares e saberes dos corpos na escola. In A. M. R. Filipouski, D. M. Marchi \& N. O. Schäffer (Orgs.). Teorias e Fazeres na Escola em Mudança. (pp.133-145). Porto Alegre: UFRGS.

Goulart, R.R., Oliveira, A.D.F. DE, Ely, C.B., Gil, L.F., Ferreira, P.F. \& Moojen, R.P. (2012). Os desafios da prática pedagógica interdisciplinar para a formação do professor de Educação Física. Do corpo: ciências e arte, 1(2), 1-23. Recuperado de: http://www.ucs.br/etc/revistas/index.php/docorpo/article/view/2304

Kronbauer, G. A., \& Nascimento, M. I. M. (2013). O circo e suas miragens: a escola nacional do circo e a história dos espetáculos na produção acadêmica brasileira. Revista HISTEDBR OnLine, 13(52), 238-249. https://doi.org/10.20396/rho.v13i52.8640240

Ontañón, T., Duprat, R., \& Bortoleto, M. (2012). Educação física e atividades circenses: "o estado da arte". Movimento (ESEFID/UFRGS), 18(2), 149-168. doi:https://doi.org/10.22456/19828918.22960 
Richter, I. M. (2012). Multiculturalidade e Interdisciplinaridade. In A. M. Barbosa (Org.), Inquietações e Mudanças no Ensino da Arte. (7 ed., pp. 95-104). São Paulo: Cortez.

Severino, A. J. (2007) Metodologia do trabalho científico (23. Ed). São Paulo: Cortez.

\section{COMO CITAR ESTE ARTIGO:}

Ost, M. A., Vianna, M., Pereira, G. S. (2020). A arte circense e seu diálogo com a Educação Física: uma experiência no Instituto Federal de Educação, Ciência e Tecnologia do Rio Grande do Sul. Holos. 36(6), 1-13.

\section{SOBRE OS AUTORES}

M. A. OST

Licenciada em Educação Física, Especialista em Pesquisa em Educação Física e Mestre em Educação Física pelo Programa de Pós-graduação em Educação Física da Universidade Federal de Pelotas.

E-mail: mariana.ost@osorio.ifrs.edu.br

ORCID ID: https://orcid.org/0000-0003-1205-210X

\section{VIANNA}

Licenciado em História pela Universidade Federal do Rio Grande do Sul. Possui especialização em Educação de Jovens e Adultos pelo Centro Universitário La Salle, mestrado e doutorado em História pela Pontifícia Universidade Católica do RS.

E-mail: marcelo.vianna@osorio.ifrs.edu.br

ORCID ID: https://orcid.org/0000-0002-3687-3474

\section{G. S. PEREIRA}

Licenciado em Letras - Português e Literaturas (UNICNEC) e Mestrando em Educação pelo Programa de Pósgraduação em Educação - PPGEd/UERGS.

E-mail: gabriel.pereira@osorio.ifrs.edu.br

ORCID ID: https://orcid.org/0000-0001-6545-9996

Editor(a) Responsável: Francinaide de Lima Silva Nascimento

Pareceristas Ad Hoc: Alison Batista e Ivana Silva

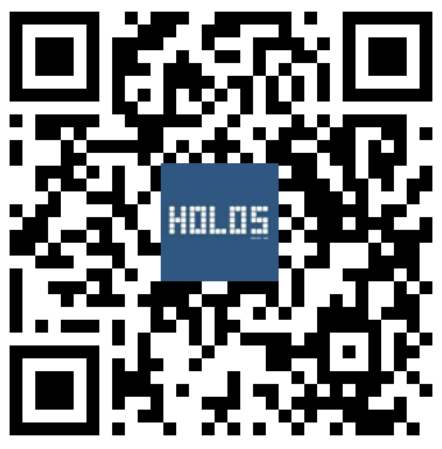

